\title{
Association of Salivary Content Alteration and Early Ageusia Symptoms in COVID-19 Infections: A Systematic Review
}

\author{
Tariq Abduljabbar ${ }^{1, \odot}$ Rana S. Alhamdan ${ }^{2, \odot}$ Modhi Al Deeb ${ }^{3, \odot} \quad$ Khulud A. AlAali, ${ }^{4, \odot ~ F a h i m ~ V o h r a ~}{ }^{1, \odot}$
}

${ }^{1}$ Department of Prosthetic Dental Science, Research Chair for Biological Research in Dental Health, College of Dentistry, King Saud University, Riyadh, Saudi Arabia

2Department of Restorative Dental Science, College of Dentistry, King Saud University, Riyadh, Saudi Arabia

${ }^{3}$ Department of Prosthetic Dental Science, College of Dentistry, King Saud University, Riyadh, Saudi Arabia

${ }^{4}$ Department of Clinical Dental Sciences, College of Dentistry, Princess Nourah Bint Abdulrahman University, Riyadh, Saudi Arabia

Eur J Dent:2020;14(suppl S1):S152-S158

\author{
Address for correspondence Fahim Vohra, PhD, MPros, MClinDent, \\ Department of Prosthetic Dental Sciences, College of Dentistry, \\ King Saud University, PO Box 60169, Riyadh 11545, Saudi Arabia \\ (e-mail: fvohra@ksu.edu.sa).
}

\begin{abstract}
Keywords

- SARS-COV-2

- COVID-19

- coronavirus

- saliva

- ageusia

- salivary gland

- viral infection

Coronavirus disease 2019 (COVID 19) is a major threat to the health and prosperity of human life at present. It has resulted in loss of thousands of lives globally and has brought countries to the brink of economic, social, and health collapse. A major issue of this infection is the ease with which it transmits through salivary droplets and its survival for long durations outside the body. Therefore, its early detection is critical in prevention, diagnostic, and management efforts of COVID-19 patients. Loss of taste and smell is one of the early symptoms reported in these patients and the virus is abundantly found in the salivary secretion of the infected symptomatic and asymptomatic patients. Infection and inflammation of salivary glands are common among viral infections, particularly in the early stages, which lead to salivary composition changes. Chemosensory sensation of taste is critically dependent on the salivary flow rate and its inorganic constituents, protein levels, specific $3^{\prime}, 5^{\prime}$-cyclic adenosine monophosphate and $3^{\prime}, 5^{\prime}$-cyclic guanosine monophosphate levels, ghrelins, pH levels, and enzymes. Therefore, the question arises, "Does COVID-19 infection alter the salivary components and composition leading to early transient symptoms of Ageusia and hypogeusia?" This review shows association of the COVID-19 and Ageusia, in addition to the early viral infection of salivary glands and possible changes in salivary flow and content. Therefore, suggesting a potential association between early ageusia in COVID-19 infection and salivary compositional changes.
\end{abstract}

\section{Introduction}

Coronavirus disease(COVID-19)infection is aglobal pandemic and its transmission is mainly through human-to-human salivary and respiratory droplets. ${ }^{1}$ It has resulted in millions of infections worldwide with more than hundred thousand deaths. It has resulted in not just loss of human life but also caused billions of dollars loss in the economy, a collapse of

DOI https://doi.org/ 10.1055/s-0040-1716986 ISSN 1305-7456. the health care systems worldwide, and rise in social and psychological disorders in large populations. ${ }^{2}$ A plethora of research is stimulated globally to find solutions with regard to prevention of transmission, diagnostic technology, early treatment, vaccination development, drug formulations, and management protocols in the form of laboratory and clinical trials. ${ }^{3}$ One critical aspect of the COVID-19 infection

(c) 2020. European Journal of Dentistry.

This is an open access article published by Thieme under the terms of the Creative Commons Attribution-NonDerivative-NonCommercial-License, permitting copying and reproduction so long as the original work is given appropriate credit. Contents may not be used for commercial purposes, or adapted, remixed, transformed or built upon. (https://creativecommons.org/licenses/by-nc-nd/4.0/)

Thieme Medical and Scientific Publishers Pvt. Ltd., A-12, 2nd Floor, Sector 2, Noida-201301 UP, India 
is its lack of early detection among infected individuals to present its transmission from asymptomatic but infected individuals. ${ }^{1,3}$ It is reported that anosmia (loss of smell) and ageusia (loss of taste) are one of the early signs of COVID-19 infections.., 5

From the earlier reports on COVID-19, ageusia is reported among more than $40 \%$ of individuals tested positive with the infection. ${ }^{6}$ Saliva and its constituents play a critical role in the oral chemosensory perception of taste sensation. Zinc deficiency is linked with hyposalivation and taste changes. ${ }^{7}$ It is reported that deficiency of a zinc-binding protein, gustin, is linked to taste bud abnormalities. ${ }^{8}$ Moreover, hypogeusia or ageusia is also associated with low levels of $3^{\prime}, 5^{\prime}$-cyclic adenosine monophosphate (cAMP) and 3',5'-cyclic guanosine monophosphate (cGMP) in the saliva, as cAMP is a possible growth factor for taste buds. ${ }^{9}$ In addition, multiple animal studies have suggested that hormones including glucagon, insulin, leptin, oxytocin, and ghrelin influence taste modalities. ${ }^{10-12}$ Moreover, in cases of low salivary flow, sweet and sour taste is not influenced; however a persistent feeling of bitterness and astringency is reported..$^{13}$ The perception of sourness falls when the $\mathrm{pH}$ increases, as the buffering capacity of saliva increases in line with the flow rate. ${ }^{14}$ Taste receptors are adapted to sodium levels in the saliva, and a threshold of sodium must be maintained for salty taste. Therefore, at high salivary flow rates, sodium concentration increases and with reabsorption in salivary ducts, sensitivity for sodium is lower. ${ }^{15,16}$ Furthermore, salivary enzymes including amylase are involved in the conversion of larger nutrients into molecules which are perceived by the taste receptors. Moreover, the presence of low salivary proteins including proline-rich proteins (PRPs) content is associated with higher percentage of astringency. ${ }^{17}$

Severe acute respiratory syndrome coronavirus 2 (SARS-CoV-2) is reported in salivary secretions of infected patients for up to 4 weeks. ${ }^{18-21}$ In addition to the viral presence in the gingival crevicular fluid (GCF) exudate and presence in oropharyngeal sputum, viral infection of the minor and major salivary glands is a possible reason for its presence in saliva. Animal studies have suggested the presence of SARS-CoV in salivary epithelial cells among infected rhesus macaques..$^{22}$ Salivary gland epithelial cells with angiotensin-converting enzyme 2 (ACE2)/cytokeratin receptors are the early target cells in the upper respiratory tract along with pneumocytes. This occurs in the early part of viral infection and is a proven source of virions in the patient saliva. ${ }^{22}$ In a study by Marder et al, parotid gland salivary constituents were assessed for proteins, electrolytes, antibodies, enzymes, and flow rate in the presence of cytomegalovirus in AIDs patients. ${ }^{23}$ Potassium, protein, and immunoglobulin A (IgA) levels were higher among infected individuals in comparison to controls. ${ }^{23}$ Suggesting that salivary gland infection can alter the salivary constituents.

It is established that salivary infections occur in the early stages of viral infections and ageusia is an early sign of SARS-CoV-2 infection. Therefore, in the presence of SARS$\mathrm{CoV}-2$ infection, it is possible that the viral infection in the salivary gland cells may alter the salivary constituents and composition. As presented earlier, salivary constituents including proteins, inorganic constituents, enzymes, hormones along with salivary flow rate, and $\mathrm{pH}$ play a critical role in taste perception. Therefore, the proposed research question is "Does COVID-19 alter the salivary components and composition leading to early transient symptoms of ageusia and hypogeusia."

Therefore, it is hypothesized that the early symptoms of ageusia among the COVID-19 patients could possibly be associated with the salivary constituent modifications due to salivary gland infections. However, to our knowledge from indexed literature, there are no studies assessing the influence of COVID-19 infection on the salivary, flow rate, $\mathrm{pH}$, and constituents in comparison to noninfected subjects with respect to ageusia. Therefore, to identify the role of COVID-19 in salivary gland infection causing an alteration of salivary components and ageusia, we present a summary of this association from available literature in a systemic manner.

\section{Materials and Methods}

This review was performed with a PubMed, Google scholar, Scopus, and EMBASE search from 1975 to 2020. The search was conducted using the following key words: Corona Virus, SARS-COV 2, Ageusia, Saliva composition, Salivary gland, and Infection. The full text of articles was obtained where possible. In case of absence of full text, the electronic files of abstract were reviewed. The inclusion criteria for the studies were articles related to viral infections and salivary content, salivary gland infection in SARS-CoV and SARS-CoV-2 infection, taste sensation and salivary constituents, gland infection, and salivary composition alteration. Case reports, articles not in English language, short summaries, and editorials were excluded.

\section{Results}

The research resulted in 122 articles. The total number of articles suitable for the review was 36 . Out of these, 22 articles were on the incidence of ageusia and COVID-19 and the remaining were reporting the association of viral infections and salivary changes, salivary composition changes and Ageusia, and salivary components related to taste changes.

\section{COVID-19 Pandemic}

The pandemic of COVID-19 is one of the greatest challenges mankind has seen in modern human history. The novel coronavirus disease started in December 2019 from the Chinese province of Wuhan infecting thousands of individuals in a matter of days. Initially considered to be a localized disease in China, the World Health Organization announced it to be a global pandemic infecting more than 200 countries around the world. ${ }^{1}$ The viral disease has infected in excess of 1.5 million humans to date and caused more than hundred thousand deaths, in addition, it is projected to infect many more for the unseen future (www.who.int.emergencies. 
Disease coronavirus). ${ }^{24}$ The devastating social, economic, and health impacts of this pandemic are unprecedented, resulting in crashing of the trading markets, trillions of dollars lost to the economy, loss of jobs for even highly skilled individuals, health care systems collapsing around the world, a stark increase in psychological and psychiatric problems, and countries nearing the brink of collapse. It has suggested by many that this viral pandemic has impacted the modern human existence to such an extent that life will not be the same in its aftermath.

\section{Coronavirus Disease 2019}

Research has suggested that COVID-19 is caused by a group of coronaviruses enveloped with a single-stranded RNA genome and a helical nucleocapsid. The genome size of coronaviruses ranges from $\sim 26$ to 32 kilobases, one of the largest among RNA viruses. ${ }^{25}$ It is officially called SARS-CoV-2. ${ }^{26}$ According to Chinese preventive medicine, it is similar to SARS-CoV and Middle eastern respiratory syndrome-CoV (MERS-CoV) with its origin in horseshoe bats and pangolins as intermediate hosts. ${ }^{27,28}$ The initial viral transmission was from animal to human followed by rapid human-to-human infection. ${ }^{29}$ The main source of transmission are respiratory droplets, personal contact, and aerosols; however, fecal-oral transmission is also reported. ${ }^{30}$ Although symptomatic patients are the main source of infection, asymptomatic carriers of virus in the 14-day incubation period are able to transmit the disease. ${ }^{27,31}$ The recent reports suggest that the fatality rate from COVID-19 ranges from 0.39 to $4.05 \%$ based on different reports from China. ${ }^{3}$ These are lower than SARS $(\approx 10 \%)$ and MERS ( $\approx 34 \%$ ) fatality rate however higher than common influenza (0.01-0.17\%) infection. ${ }^{32}$ The symptoms of COVID-19 in majority of cases are mild, including fever, cough, muscle pain, fatigue, headache, vomiting, diarrhea, sore throat, and shortness of breath. ${ }^{33}$ In some cases, a transient change of taste or total loss is also reported in COVID-19 patients. However, one-fourth of the symptomatic patients develops severe symptoms of respiratory distress syndrome, shock, and arrhythmia. ${ }^{34}$ It is widely believed that patients with diabetes, hypertension, cardiovascular disease, and underlying comorbidities are associated with poor prognosis and in some cases death. ${ }^{35}$ Currently, there is no specific and standard anti-CoV treatment strategy based on randomized trials and major management is supportive. This includes early diagnosis, limiting the infection symptoms with antibiotics, antipyretics and limiting transmission with quarantine, isolation, and disinfection. Potentially effective drugs on which trials are being conducted include antiviral therapies such as lopinavir and remdesivir. ${ }^{29}$

\section{Diagnosis of COVID-19}

Diagnosis of COVID-19 is primarily by epidemiological information such as history of travel or close contact with infected patient followed by reverse transcription polymerase chain reaction on nasopharyngeal swabs, sputum, or saliva and computed tomography imaging of the infected lungs. Expectorated sputum respiratory tract samples in patients with lower respiratory tract infections are the primary used for testing. ${ }^{36}$ As transmission is primarily through aerosol salivary droplets entering the body via oral or nasal pathways, saliva is the primary carrier and mode for viral transfer. Studies have suggested that SARS-CoV-2 has been detected in saliva of COVID-19 patients. ${ }^{37}$ Viral strains have been detected in saliva of infected patients up to 4 weeks of infection, indicating that diagnosis using salivary platforms is possible. ${ }^{19}$ Salivary collection is noninvasive, and does not require the close contact between the infected patient and health care workers, therefore, reducing the transmission of infection. In addition, production of oropharyngeal samples of sputum requires exertion and may cause bleeding, and according to one report can only be produced in $28 \%$ of infected patients. Suggesting that self-collection of saliva for patients with nasopharyngeal symptoms is a much easier method of viral detection with low risk and less trauma. SARS-CoV-2 is present in the saliva, as its main path of transmission is a liquid droplet through the oral cavity. Moreover, the viral RNA present in the blood can enter saliva through the exudate from GCF containing proteins and extracellular matrix. ${ }^{38}$ However, it still needs to be assessed if use of salivary fluid in viral detection of COVID-19 is an effective and efficient method.

\section{Occurrence of Ageusia (Loss of Taste) in COVID-19}

One of the initial symptoms in COVID-19 infections as reported in various early reports are anosmia (loss of smell) and ageusia (loss of taste). ${ }^{4}$ These symptoms are associated with respiratory infections, trauma, oncology treatments, nasal polyps, and use of medications. ${ }^{4,5} \mathrm{~A}$ report by Prof. Claire Hopkins, King's College London, Guy's and St Thomas' Hospital, Department of Ear, Nose, and Throat suggested anosmia and ageusia as a viral occurrence in $40 \%$ of cases. ${ }^{6}$ It was also suggested that within a cohort of 2,000 COVID-19 patients in South Korea, 30\% showed symptoms of anosmia or ageusia, indicating it as a trigger for self-isolation. ${ }^{6}$

\section{Association of Saliva and Ageusia}

Saliva and its constituents play a critical role in the oral chemosensory perception (-Table $\mathbf{1}$ ). It is a complex fluid compound mixture of glandular secretions, food particles, GCF exudate, and complex proteins. The food bolus is $50 \%$ saliva and the interaction between sensory cells for taste sensation and oral contents is not just intrinsic food particles but a major portion is salivary contents. Taste sensation is produced when volatile substances come in contact with taste bud receptors. Taste buds are mainly present on the tongue papillae in proximity to the minor salivary glands. Salivary fluids dissolve the food particles and bathe the taste buds, initiating taste perception. The basic five-taste senses include sweet, salty, bitter, sour, and umami. Saliva is considered to protect and modulate taste sensation through receptors. Zinc deficiency is linked with hyposalivation and taste changes. ${ }^{7}$ It is reported that deficiency of a zinc-binding protein, Gustin, is linked to taste bud abnormalities. ${ }^{8} \mathrm{~A}$ global oral sensitivity molecule, 6-n-propylthiouracil was recently reported to be inversely related to zinc concentration in saliva, associated 
Table 1 Association of salivary constituent changes and ageusia

\begin{tabular}{|c|c|c|}
\hline Salivary constituent & Function & Association with taste change and ageusia \\
\hline Zn ions & $\begin{array}{l}\text { - Metabolic agent } \\
\text { - Antibacterial } \\
\text { - Taste sensation }\end{array}$ & $\begin{array}{l}\text { - Deficiency of Zn; hypogeusia, hyposalivation } \\
\text { - } 6 \text {-n-propylthiouracil sensitivity is inversely related to Zn } \\
\text { concentration }\end{array}$ \\
\hline Gustin (Zn-binding protein) & $\begin{array}{l}\text { - Zn-binding protein } \\
\text { - Development of taste buds }\end{array}$ & - Inhibition of its synthesis causes taste bud abnormalities \\
\hline $\begin{array}{l}\text { CAMP } \\
\text { cGMP }\end{array}$ & $\begin{array}{l}\text { - Growth of taste buds } \\
\text { - Nutrient and sensor in } \\
\text { hypothalamus } \\
\text { - Interacts with } \mathrm{Ca}^{+} \text {and proteins, } \\
\text { signaling of chemosensory } \\
\text { transduction }\end{array}$ & $\begin{array}{l}\text { CAMP and cGMP inhibition } \\
\text { - Causes taste bud abnormalities } \\
\text { - Hypogeusia } \\
\text { - Ageusia }\end{array}$ \\
\hline $\begin{array}{l}\text { Salivary hormones } \\
\text { - Glucagon } \\
\text { - Leptin } \\
\text { - Ghrelin } \\
\text { - Insulin }\end{array}$ & $\begin{array}{l}\text { - Modulation of taste } \\
\text { perception }\end{array}$ & $\begin{array}{l}\text { - Lack of glucagon causes reduce response to sucrose } \\
\text { - Increase of leptin suppresses sweet sensation } \\
\text { - Lack of ghrelin causes reduced sour and salty taste } \\
\text { - Presence of salivary insulin enhances salty taste }\end{array}$ \\
\hline $\begin{array}{l}\text { Electrolytes } \\
-\mathrm{NaCl} \\
-\mathrm{K}^{+} \\
-\mathrm{MG}\end{array}$ & $\begin{array}{l}\text { - } \text { Regulate } \mathrm{pH} \\
\text { - Maintain flow rate } \\
\text { - } \text { Regulate taste }\end{array}$ & $\begin{array}{l}\text { - Taste adaptation due to salivary concentration } \\
\text { - Low MG makes umami taste unpleasant }\end{array}$ \\
\hline $\begin{array}{l}\text { Enzymes } \\
\text { - Amylase } \\
\text { - Protease } \\
\text { - Lipase }\end{array}$ & $\begin{array}{l}\text { - Digestive of nutrients } \\
\text { - Conversion of micronutri- } \\
\text { ents into perceivable taste } \\
\text { molecules }\end{array}$ & $\begin{array}{l}\text { - Higher caffeine perception with lower protease levels } \\
\text { - } \text { Increased amylase causes hydrolysis of starch to maltose, } \\
\text { reducing sweet taste } \\
\text { - } \text { Amylase activity reduces salty taste }\end{array}$ \\
\hline $\begin{array}{l}\text { Proteins } \\
\text { - PRPs } \\
\text { - vEGP }\end{array}$ & $\begin{array}{l}\text { - Salivary binding of mole- } \\
\text { cules (tannins) } \\
\text { - Assist in digestion } \\
\text { - Binding aroma compounds } \\
\text { to olfactory receptors }\end{array}$ & $\begin{array}{l}\text { - Low salivary protein shows high astringency } \\
\text { - PRPs supplements show high response to bitter taste } \\
\text { - PRPs supplements show perception of roughness } \\
\text { - VEGP discrepancy can cause low perception of fatty taste }\end{array}$ \\
\hline Flow rate & $\begin{array}{l}\text { - } \text { Maintain concentration of } \\
\text { taste compounds } \\
\text { - Protection of taste buds } \\
\text { - Taste perception, interac- } \\
\text { tion with sensory stimuli }\end{array}$ & $\begin{array}{l}\text { Low flow rate is associated with } \\
\text { - Bitter taste } \\
\text { - Astringency } \\
\text { - Increase flow rate is associated with reduced } \\
\text { - Sour taste } \\
\text { - Salty taste }\end{array}$ \\
\hline
\end{tabular}

Abbreviations: cAMP, 3',5'-cyclic adenosine monophosphate; cGMP, 3',5'-cyclic guanosine monophosphate; MG, monosodium glutamate; PRPs, proline-rich proteins; vEGP, von Ebner Gland protein; Zn, zinc.

with polymorphism of gustin gene. ${ }^{39}$ Moreover, hypogeusia or ageusia is also associated with low levels of cAMP and cGMP in the saliva, as cAMP is a possible growth factor for taste buds. ${ }^{9}$ cAMP and cGMP play a critical role in chemosensory transduction. ${ }^{40}$ cGMP is suggested to be vital in interaction with $\mathrm{Ca}$ and proteins in signaling of the gustatory and olfactory systems. ${ }^{41,42}$ A cAMP-activated protein kinase acts as a nutrient and sensor in the hypothalamus, and it activates cell surface and send signals in association with $G$ proteins. ${ }^{43,44}$

\section{Salivary Hormones and Ageusia}

Salivary hormones are also implicated in the development of taste buds and possibly influence the taste sensation. Multiple animal studies have suggested that hormones including glucagon, insulin, leptin, oxytocin, and ghrelin influence taste modalities. ${ }^{10-12}$ Glucagon and leptin have shown to modulate sweet taste by suppressing response to peripheral taste receptors. ${ }^{45,46}$ In addition, salivary insulin is shown to augment the salty taste, however, lack of ghrelin compromises sour (citric acid) and salty taste. ${ }^{47,48}$

\section{Flow Rate, Inorganic Components of Saliva, and Ageusia}

Interestingly, salivary flow rate is linked to the taste sensation. The concentration of taste compounds is influenced by volume of saliva at the receptors. ${ }^{49}$ In cases of low salivary flow, sweet and sour taste is not influenced; however, a persistent feeling of bitterness and astringency is reported. ${ }^{13}$ The salivary flow rate, by addition of artificial saliva, has shown a reduction in the perception 
of citric acid (sour) and sodium chloride; however, this could be due to salivary dilution. ${ }^{50}$ Inorganic compounds of saliva are also related to taste perception, for instance, minerals in saliva, especially sodium. The taste receptors are adapted to the sodium levels in the saliva, and for salty taste to be produced a threshold of sodium must be maintained. As a result at high salivary flow rates, sodium concentration increases and with reabsorption in salivary ducts, sensitivity for sodium is lower. ${ }^{16,51}$ Other substances, such as monosodium glutamate, are also associated with heightened taste perception of umami. ${ }^{52}$ Furthermore, one of the main functions of saliva is regulation of oral $\mathrm{pH}$ by producing bicarbonate. The perception of sourness falls when the $\mathrm{pH}$ increases, as the buffering capacity of saliva increases in line with the flow rate. ${ }^{14}$

\section{Salivary Enzymes and Ageusia}

Salivary enzymes including amylase, protease, and lipases are connected to taste perception of food. They are involved in the conversion of larger nutrients into molecules, which are perceived by the taste receptors. Hydrolysis of triglycerides in the diet with lipases release fatty acids which can be perceived by the taste system. ${ }^{53}$ A protease inhibitor, cystatin-SN, is reported to be associated with perception of caffeine. ${ }^{54}$ Moreover, a relation between reduced salty taste and amylase activity in $\mathrm{NaCl}$ containing starch food is suggested. ${ }^{55}$ Therefore, in addition to digestion, these enzymes (amylase, protease, and lipase) play an important role in maintaining normal taste perception.

\section{Salivary Proteins and Ageusia}

Also, of concern, some of the salivary-binding proteins including PRPs are reported to be associated with astringency. PRPs are intrinsically produced and bind with tannins to prevent their digestive complications. ${ }^{56}$ Therefore, based on this mechanism, the presence of low salivary protein content is associated with higher percentage of astringency. ${ }^{17}$ PRPs are also implicated in the perception of taste, a study suggested that supplementation of PRPs (Ps-1) in patients with low Ps-1 displayed high response to bitter taste. ${ }^{57}$

\section{Salivary Gland Infection and Salivary Composition}

As suggested before that SARS-COV-2 is reported in salivary secretions of infected patients for up to 4 weeks. ${ }^{18,19}$ In addition to the viral presence in the GCF exudate and presence in oropharyngeal sputum, viral infection of the minor and major salivary glands is a possible reason for its presence in saliva. Animal studies have suggested the presence of SARS-CoV in salivary epithelial cells among infected rhesus macaques. ${ }^{22}$ It is also reported that viral-specific IgA is produced in saliva of animal models intranasal immunized, further supporting the viral presence. ${ }^{58}$ Salivary gland epithelial cells with ACE2/cytokeratin receptors are the early target cells in the upper respiratory tract along with pneumocytes. This occurs in the early part of viral infection and is a proven source of virions in the patient saliva. ${ }^{59}$ Salivary gland constituents and composition can be influenced by the viral infections of the gland. In a study by Marder et al, parotid gland salivary constituents were assessed for proteins, electrolytes, antibodies, enzymes, and flow rate in the presence of cytomegalovirus in human immunodeficiency virus patients. ${ }^{23}$ Potassium, protein, and $\operatorname{Ig}$ A levels were higher among infected individuals in comparison to controls. ${ }^{23}$ Suggesting that salivary gland infection can alter the salivary constituents.

\section{Recommendations for Future Studies}

The presented association of COVID-19 salivary alterations and ageusia suggest that all precautions should be taken to avoid salivary contamination and droplet infections of SARS-CoV-2 and salivary gland infections. Limited evidence is available on assessing the influence of COVID-19 infection on the salivary, flow rate, $\mathrm{pH}$, protein (PRPs), inorganic constituents (sodium, potassium, and zinc), immunoglobulin, enzymes (protease, amylase, and lipase), and hormone (insulin, glucagon, ghrelin, and leptin) levels in comparison to noninfected subjects. Future studies can correlate salivary changes in COVID-19 infection and ageusia as a novel finding. In addition, correlation of salivary constituent changes and early symptoms of COVID-19 (ageusia) will allow early diagnosis of SARS-CoV-2 infected patients and prevention of disease transmission. Studies can also explore the causes of ageusia and anosmia in COVID-19 disease and the association of cAMP and cGMP in taste bud and sensory cells growth in COVID-19.

\section{Conclusion}

Literature suggests that ageusia is associated with COVID-19 infections and the viral infection of the salivary gland cells may alter the salivary constituents and composition. Salivary constituents including proteins, inorganic constituents, enzymes, hormones along with salivary flow rate, and $\mathrm{pH}$ play a critical role in taste perception. Therefore, the early symptoms of ageusia among the COVID-19 patients are potentially associated with the salivary constituent modifications due to salivary gland infections.

\section{Conflict of Interest}

None declared.

\section{Acknowledgment}

The authors are grateful to the Deanship of Scientific Research, King Saud University for funding through Vice Deanship of Scientific Research Chairs, Research Chair for Biological Research in Dental Health.

\section{References}

1 World Health Organization. 2020b. Coronavirus disease 2019 (COVID-19): situation report-36. Available at: https:// www.who.int/docs/default-source/coronaviruse/situationreports/20200225-sitrep-36-covid-19.

2 van Staden C. COVID-19 and the crisis of national development. Nat Hum Behav 2020;4(5):443-444 
3 Centers for Disease Control and Prevention. 2020. Disease burden of influenza. Available at: https://www.cdc.gov/flu/ about/burden/ index.html. February https://www.cdc.gov/ coronavirus/2019-ncov/index.html

4 Russell B, Moss C, Rigg A, Hopkins C, Papa S, Van Hemelrijck M. Anosmia and ageusia are emerging as symptoms in patients with COVID-19: What does the current evidence say?. Ecancermedicalscience 2020;14:ed98 doi:10.3332/ecancer.2020.ed98

5 Rabin R. Lost sense of smell may be peculiar clue to coronavirus infection.TheNewYorkTimes.Availableat: https://www.nytimes. com/2020/03/22/ health/coronavirus-symptoms-smell-taste. html. Accessed March 26, 2020

6 Hopkins C, Kumar N. Loss of sense of smell as marker of COVID-19 infection. https://www.entuk.org/sites/default/ files/files/Loss $\% 20$ of $\% 20$ sense $\% 20$ of $\% 20$ smell\%20as\%20 marker\%20of\%20COVID.pdf Available at: https://www.entuk. org/sites/default/ files/files/Loss of sense of smell as marker of COVID.pdf. Accessed March 26, 2020

7 Henkin RI, Bradley DF. Hypogeusia corrected by $\mathrm{Ni++}$ and Zn++. Life Sci II 1970;9(12):701-709

8 Henkin RI, Martin BM, Agarwal RP. Decreased parotid saliva gustin/carbonic anhydrase VI secretion: an enzyme disorder manifested by gustatory and olfactory dysfunction. Am J Med Sci 1999;318(6):380-391

9 Henkin RI, Velicu I. Differences between and within human parotid saliva and nasal mucus CAMP and cGMP in normal subjects and in patients with taste and smell dysfunction. J Oral Pathol Med 2011;40(6):504-509

10 De Matteis R, Puxeddu R, Riva A, Cinti S. Intralobular ducts of human major salivary glands contain leptin and its receptor. J Anat 2002;201(5):363-370

11 Aydin S, Halifeoglu I, Ozercan IH, et al. A comparison of leptin and ghrelin levels in plasma and saliva of young healthy subjects. Peptides 2005;26(4):647-652

12 White-Traut R, Watanabe K, Pournajafi-Nazarloo H, Schwertz D, Bell A, Carter CS. Detection of salivary oxytocin levels in lactating women. Dev Psychobiol 2009;51(4):367-373

13 Fischer U, Boulton RB, Noble AC. Physiological factors contributing to the variability of sensory assessments: relationship between salivary flow rate and temporal perception of gustatory stimuli. Food Qual Prefer 1994;5:55-64

14 Neyraud E, Bult JHF, Dransfield E. Continuous analysis of parotid saliva during resting and short-duration simulated chewing. Arch Oral Biol 2009;54(5):449-456

15 Poulsen JH, Secretion of electrolytes and water by salivary glands. In: Garret JR, Ekström J, Anderson LC, eds. Glandular Mechanisms of Salivary Secretion. Basel: Karger; 1998:55-72

16 Delwiche J, O'Mahony M. Changes in secreted salivary sodium are sufficient to alter salt taste sensitivity: use of signal detection measures with continuous monitoring of the oral environment. Physiol Behav 1996;59(4-5):605-611

17 Canon F, Paté F, Cheynier V, et al. Aggregation of the salivary proline-rich protein IB5 in the presence of the tannin EgCG. Langmuir 2013;29(6):1926-1937

18 Ahmed N, Maqsood A, Abduljabbar T, Vohra F. Tobacco smoking a potential risk factor in transmission of COVID-19 infection. Pak J Med Sci 2020;36(COVID19-S4) :S104-S107

19 Zuanazzi D, Arts EJ,Jorge PK, et al. Postnatal identification ofZika virus peptides from saliva. J Dent Res 2017;96(10):1078-1084

20 Ali S, Noreen S, Farooq I, Bugshan A, Vohra F. Risk assessment of healthcare workers at the frontline against COVID-19. Pak J Med Sci 2020;36(COVID19-S4) :S99-S103

21 Ahmed N, Shakoor M, Vohra F, Abduljabbar T, Mariam Q, Rehman MA. Knowledge, awareness and practice of health care professionals amid SARS-CoV-2, corona virus disease outbreak. Pak J Med Sci 2020;36(COVID19-S4) :S49-S56
22 Liu L, Wei Q, Alvarez X, et al. Epithelial cells lining salivary gland ducts are early target cells of severe acute respiratory syndrome coronavirus infection in the upper respiratory tracts of rhesus macaques. J Virol 2011;85(8):4025-4030

23 Marder MZ, Barr CE, Mandel ID. Cytomegalovirus presence and salivary composition in acquired immunodeficiency syndrome. Oral Surg Oral Med Oral Pathol 1985;60(4):372-376

24 World Health Organization. 2020b. Coronavirus disease 2019 (COVID-19). Available at: https://www.who.int/emergencies/ diseases/novel-coronavirus-2019/events-as-they-happen// www.who.int/emergencies/diseases/novel-coronavirus-2019/ events-as-they-happen.

25 Woo PCY, Huang Y, Lau SKP, Yuen KY. Coronavirus genomics and bioinformatics analysis. Viruses 2010;2(8):1804-1820

26 Meng L, Hua F, Bian Z. Coronavirus disease 2019 (COVID-19): emerging and future challenges for dental and oral medicine. J Dent Res 2020;99(5):481-487

27 Chan JF, Yuan S, Kok KH, et al. A familial cluster of pneumonia associated with the 2019 novel coronavirus indicating person-to-person transmission: a study of a family cluster. Lancet 2020;395(10223):514-523

28 Lu R, Zhao X, Li J, et al. Genomic characterisation and epidemiology of 2019 novel coronavirus: implications for virus origins and receptor binding. Lancet 2020;395(10224):565-574

29 Del Rio C, Malani PN. 2019 Novel coronavirus-important information for clinicians. JAMA 2020;323(11):1039-1040 doi:10.1001/jama.2020.1490

30 Holshue ML, DeBolt C, Lindquist S, et al; Washington State 2019nCoV Case Investigation Team. First case of 2019 novel coronavirus in the United States. N Engl J Med 2020;382(10):929-936

31 Rothe C, Schunk M, Sothmann P, et al. Transmission of 2019-nCoV infection from an asymptomatic contact in Germany. N Engl J Med 2020;382(10):970-971

32 Malik YS, Sircar S, Bhat S, et al. Emerging novel coronavirus (2019-nCoV)-current scenario, evolutionary perspective based on genome analysis and recent developments. Vet Q 2020;40(1):68-76

33 Guan WJ, Ni ZY, Hu Y, et al. Clinical characteristics of 2019 novel coronavirus infection in China. medRxiv. Available at: https://www.medrxiv.org/content/10.1101/2020.02.06.20020 974v1. Accessed 22 May 2020

34 Wang $\mathrm{D}, \mathrm{Hu} \mathrm{B}, \mathrm{Hu} \mathrm{C}$, et al. Clinical characteristics of 138 hospitalized patients with 2019 novel coronavirus-infected pneumonia in Wuhan, China. JAMA 2020;323(11):1061-1069

35 Liu K, Fang YY, Deng Y, et al. Clinical characteristics of novel coronavirus cases in tertiary hospitals in Hubei Province. Chin Med J (Engl) 2020;133(9):1025-1031

36 ECDC - European Centre for Disease Prevention and Control. European surveillance for human infection with novel coronavirus (COVID-19). Available at: https://www.ecdc.europa. eu/en/european-surveillance-humaninfection-novel-coronavirus-COVID-19. Accessed January 28, 2020

37 To KK, Tsang OT, Yip CC, et al. Consistent Detection of 2019 Novel Coronavirus in Saliva. Clin Infect Dis 2020;71(15):841843 doi:10.1093/cid/ciaa149

38 Silva-Boghossian CM, Colombo AP, Tanaka M, Rayo C, Xiao Y, Siqueira WL. Quantitative proteomic analysis of gingival crevicular fluid in different periodontal conditions. PLoS One 2013;8(10):e75898

39 PadigliaA,ZonzaA,AtzoriE, etal.Sensitivity to6-n-propylthiouracil is associated with gustin (carbonic anhydrase VI) gene polymorphism, salivary zinc, and body mass index in humans. Am J Clin Nutr 2010;92(3):539-545

40 Henkin RI, Velicu I, Papathanassiu A. cAMP and cGMP in human parotid saliva: relationships to taste and smell dysfunction, gender, and age. Am J Med Sci 2007;334(6): 431-440 
41 Shepherd GM. Sensory transduction: entering the mainstream of membrane signaling. Cell 1991;67(5):845-851

42 Rosenzweig S, Yan W, Dasso M, Spielman AI. Possible novel mechanism for bitter taste mediated through cGMP. J Neurophysiol 1999;81(4):1661-1665

43 Oyama M, Blumberg DD. Interaction of cAMP with the cell-surface receptor induces cell-type-specific mRNA accumulation in Dictyostelium discoideum. Proc Natl Acad Sci U S A 1986;83(13):4819-4823

44 HanSM,NamkoongC,JangPG,etal.HypothalamicAMP-activated protein kinase mediates counter-regulatory responses to hypoglycaemia in rats. Diabetologia 2005;48(10):2170-2178

45 Zolotukhin S. Metabolic hormones in saliva: origins and functions. Oral Dis 2013;19(3):219-229

46 Elson AET, Dotson CD, Egan JM, Munger SD. Glucagon signaling modulates sweet taste responsiveness. FASEB J 2010;24(10):3960-3969

47 Shin YK, Martin B, Kim W, et al. Ghrelin is produced in taste cells and ghrelin receptor null mice show reduced taste responsivity to salty $(\mathrm{NaCl})$ and sour (citric acid) tastants. PLoS One 2010;5(9):e12729

48 Baquero AF, Gilbertson TA. Insulin activates epithelial sodium channel (ENaC) via phosphoinositide 3-kinase in mammalian taste receptor cells. Am J Physiol Cell Physiol 2011;300(4):C860-C871

49 Neyraud E, Prinz J, Dransfield E. $\mathrm{NaCl}$ and sugar release, salivation and taste during mastication of salted chewing gum. Physiol Behav 2003;79(4-5):731-737

50 Heinzerling CI, Stieger M, Bult JHF, Smit G. Individually modified saliva delivery changes the perceived intensity of saltiness and sourness. Chemosens Percept 2011;4(4):145-153
51 Poulsen JH, Secretion of electrolytes and water by salivary glands. In: Garret JR, Ekström J, Anderson LC, eds. Glandular Mechanisms of Salivary Secretion. Basel: Karger; 1998 55-72

52 Scinska-Bienkowska A, Wrobel E, Turzynska D, et al. Glutamate concentration in whole saliva and taste responses to monosodium glutamate in humans. Nutr Neurosci 2006;9(1-2):25-31

53 Neyraud E, Palicki O, Schwartz C, Nicklaus S, Feron G. Variability of human saliva composition: possible relationships with fat perception and liking. Arch Oral Biol 2012;57(5):556-566

54 Dsamou M, Palicki O, Septier C, et al. Salivary protein profiles and sensitivity to the bitter taste of caffeine. Chem Senses 2012;37(1):87-95

55 Ferry ALS, Mitchell JR, Hort J, et al. In-mouth amylase activity can reduce perception of saltiness in starch-thickened foods. J Agric Food Chem 2006;54(23):8869-8873

56 Canon F, Ballivian R, Chirot F, et al. Folding of a salivary intrinsically disordered protein upon binding to tannins. J Am Chem Soc 2011;133(20):7847-7852

57 Melis M, Aragoni MC, Arca M, et al. Marked increase in PROP taste responsiveness following oral supplementation with selected salivary proteins or their related free amino acids. PLoS One 2013;8(3):e59810

58 LuB, Huang Y, Huang L, et al. Effect of mucosal and systemic immunization with virus-like particles of severe acute respiratory syndrome coronavirus in mice. Immunology 2010;130(2):254-261

59 Liuzzi G, Chirianni A, Clementi M, et al. Analysis of HIV-1 load in blood, semen and saliva: evidence for different viral compartments in a cross-sectional and longitudinal study. AIDS 1996;10(14):F51-F56 